\title{
Thin films of titanium dioxide: morphology and phase structure
}

\author{
A.Yu. Stepanov ${ }^{1}$, A.A. Vladimirov ${ }^{1,2}$, A.N. Popova ${ }^{2,3, \dagger}$, L.V. Sotnikova ${ }^{2,1}$ \\ th991@yandex.ru \\ ${ }^{1}$ Kemerovo State University, Krasnaya str., 6, 650043 Kemerovo, Russia \\ ${ }^{2}$ Kemerovo Scientific Center SB RAS, Soviet pr., 18, 650000 Kemerovo, Russia \\ ${ }^{3}$ Institute of Coal Chemistry and Material Science SB RAS, Soviet pr., 18, 650000 Kemerovo, Russia
}

The article is devoted to the study of the morphology and structure of the thin films of titanium dioxide obtained by thermal decomposition of the organotitanium precursor films. $\mathrm{TiO}_{2}$ thin films were obtained using activated decomposition of organotitanium precursor films. As organotitanium precursor it is used solution of polyetoxititanium alcoholic which has been prepared by polycondensation in the presence of water during preparation solution of titanium tetrachloride $\mathrm{TiCl}_{4}$ in ethanol. Precursor films were treated by UV irradiation to obtain TiO2 amorphous films. AMT-125 lamps were used for pattern irradiation. Due to precursor film thermolysis at a predetermined temperature $\left(300-500^{\circ} \mathrm{C}\right)$ in SNOL $15 / 1300$ muffle furnace crystalline $\mathrm{TiO}_{2}$ films were formed. X-ray diffraction analysis (XRD), scanning electron microscopy (SEM), atomic-force microscopy (AFM) were used to study crystalline structure and morphology of the obtained amorphous and crystalline $\mathrm{TiO}_{2}$ films. Films substrates varied depending on the study method. XRD and AFM methods show that it is real obtain $\mathrm{TiO}_{2}$ films with well-crystallized structure of anatase stable in the temperature range $400-500^{\circ} \mathrm{C}$. It is found by study of the surface morphology of anatase film that the surface is formed with (101) crystallographic indices. It is shown the possibility to obtain transparent crystalline $\mathrm{TiO}_{2}$ films with given structural modification at controlled heating to study $\mathrm{TiO}_{2}$ surface morphology influence on topochemical reactions. Amorphous and crystalline anatase and anatase-rutile $\mathrm{TiO}_{2}$ films with different phase ratio were obtained. The surface of morphologically homogeneous anatase crystalline films with ordered surface (101) structure was studied, the temperature of film formation was determined. The results show the possibility to obtain crystalline anatase $\mathrm{TiO}_{2}$ thin films on glass and brass substrates. The structure of the obtained films is homogeneous in thickness and morphology. Precursor film deposition method and conditions of $\mathrm{TiO}_{2}$ films formation allow to deposit them on different surfaces to impart photocatalytic properties.

Keywords: thin films, titanium dioxide, $\mathrm{TiO}_{2}$, anatase, crystal surface

\section{Исследование морфологии и фазового состава тонких пленок диоксида титана}

\author{
Степанов А.Ю. ${ }^{1}$, Владимиров А.А. ${ }^{1,2}$, Попова А.Н., ${ }^{2,+\dagger}$, Сотникова Л.В. ${ }^{2,1}$ \\ †h991@yandex.ru \\ ${ }^{1}$ Кемеровский государственный университет, ул. Красная 6, 650043, г. Кемерово, Россия \\ ${ }^{2}$ Кемеровский научный центр СО РАН, пр. Советский, 18, 650000, Кемерово, Россия \\ ${ }^{3}$ Институт углехимии и химического материаловедения, пр. Советский, 18, 650000, Кемерово, Россия
}

В данной статье представлены результаты исследования морфологии и структуры тонких пленок диоксида титана, полученных термическим разложением пленок титанорганического прекурсора. Тонкие пленки ТіО, получали методом термического разложения пленок титанорганического прекурсора. В качестве титанорганического прекурсора использовали спиртовый раствор полиэтоксититана, который получали по реакции поликонденсации в присутствии воды. Образование кристаллических пленок $\mathrm{TiO}_{2}$ происходило в результате термолиза пленок прекурсора при температурах от $300^{\circ} \mathrm{C}$ до $500^{\circ} \mathrm{C}$ в муфельной печи СНОЛ 15/1300. Исследование кристаллической структуры и морфологии полученных кристаллических пленок $\mathrm{TiO}_{2}$ проводили методами рентгенофазового анализа (РФА), сканирующей электронной микроскопии (СЭМ), атомно-силовой микроскопии (АСМ). Методами РФА и АСМ показана возможность получения хорошо окристаллизованных пленок $\mathrm{TiO}_{2}$ со структурой анатаза стабильных в интервале температур $400-500^{\circ} \mathrm{C}$. Изучение морфологии поверхности пленок анатаза, показало формирование поверхности с кристаллографическими индексами (101). Показана возможность получения прозрачных кристаллических пленок 
$\mathrm{TiO}_{2}$ с заданной структурной модификацией в условиях контролируемого нагрева с целью последующего изучения влияния морфологии поверхности $\mathrm{TiO}_{2}$ на протекание топохимических реакций. Получены аморфные и кристаллические со структурной модификацией анатаз или анатаз-рутил с различным соотношением фаз пленки ТіО 2 . Исследована поверхность морфологически однородных кристаллических пленок анатаза с упорядоченной структурой поверхности (101), определена температура их формирования в вакууме и на воздухе. Полученные результаты показывают возможность получения тонких кристаллических пленок диоксида титана в модификации анатаз на подложках из стекла и меди. Структура полученных пленок однородная по толщине и морфологии. Способ нанесения пленки прекурсора и условия формирования пленок $\mathrm{TiO}_{2}$ позволяют наносить их на металлические и стеклянные поверхности для придания им фотокаталитических свойств.

Ключевые слова: тонкие пленки, диоксид титана, $\mathrm{TiO}_{2}$, анатаз, кристаллические поверхности.

\section{1. Введение}

Фотохимическая активность наночастиц $\mathrm{TiO}_{2}$ в каталитических реакциях под действием УФ-света, как было неоднократно подчеркнуто в различных источниках, зависит от условий их получения [1-6]. Согласно общепринятому мнению, такая зависимость обусловлена влиянием фазового состава и размера частиц $\mathrm{TiO}_{2}$, которые и задаются условиями синтеза. Поскольку учесть все нюансы строения наноразмерных порошков $\mathrm{TiO}_{2}$ не представляется возможным, для сравнения фотокаталитической активности различных экспериментальных образцов принято использовать компаратив, в качестве которого чаще всего выступает промышленно выпускаемый фотокатализатор Aeroxide $\mathrm{TiO}_{2} \mathrm{P} 25$ фирмы Evonik. Такой эмпирический подход к получению высокоэффективных фотокатализаторов оправдан практическим интересом, однако получаемые при этом данные не позволяют полностью объяснить механизм изменения эффективности топохимических реакций на поверхности наноразмерных частиц $\mathrm{TiO}_{2}$.

В последнее время усилия ученых разных стран направлены на получение кристаллических частиц $\mathrm{TiO}_{2}$ различных структурных модификаций с выраженным кристаллическим строением и формой [7-10]. С получением таких частиц связывают надежды на повышение эффективности фотокатализаторов на основе $\mathrm{TiO}_{2}$ за счет получения частиц с содержанием большего количества граней с повышенной реакционной активностью.

Однако, кристаллические поверхности с повышенной реакционной активностью, как правило, исчезают в процессе роста кристалла, в результате минимизации поверхностной энергии $[7,9]$. Поэтому для $\mathrm{TiO}_{2}$ в фотоактивной модификации анатаз, характерно формирование частиц с преобладанием термодинамически стабильных граней (101).

Было установлено [7], что стабилизатором (001) граней анатаза является плавиковая кислота, а полученные в ее присутствии частицы анатаза с высоким содержанием граней (001) показали более высокую каталитическую активность [9]. Позднее было обнаружено [11, 12], что высокая активность граней (001) связана с наличием на их поверхности остаточного фтора, который способствует усилению адсорбции кислорода фторированными гранями. Авторы полагают, что увеличение концентрации адсорбированного кислорода способствует значительно более эффективному разделению фотогене- рируемых зарядов и, как следствие, росту фотокаталитической активности.

Дальнейшее изучение сравнительной каталитической активности термодинамически стабильных и нестабильных граней различных кристаллических модификаций $\mathrm{TiO}_{2}$ представляет научный и практический интерес. Однако, проведение такого исследования является сложной задачей, трудность которой состоит в получении морфологически однородных поверхностей $\mathrm{TiO}_{2}$ с заданными кристаллографическими индексами. Другая сложность связана с разработкой методов наблюдения за топохимическими реакциями на частицах нанометрового размера. В тоже время полученные нами ранее [13] морфологически однородные тонкие пленки $\mathrm{TiO}_{2}$ с выраженной кристаллической структурой позволяют надеяться, что с использованием различных стабилизаторов поверхности могут быть получены пленки для проведения модельных экспериментов по выявлению зависимости активности и локализации продуктов топохимических реакций от структуры кристаллической поверхности $\mathrm{TiO}_{2}$.

В настоящей работе представлены результаты исследования морфологии и кристаллической структуры поверхности тонких пленок $\mathrm{TiO}_{2}$, полученных методом термического разложения пленок титанорганического прекурсора на подложках различной природы.

\section{2. Эксперимент}

Тонкие пленки $\mathrm{TiO}_{2}$ получали методом термического разложения пленок титанорганического прекурсора. В качестве титанорганического прекурсора использовали спиртовый раствор полиэтоксититана, который получали по реакции поликонденсации в присутствии воды в процессе приготовлении 30\%, в пересчете на $\mathrm{TiO}_{2}$, раствора тетрахлорида титана $\mathrm{TiCl}_{4}$ в этиловом спирте. Раствор необходимый для формирования пленок прекурсора получали из исходного $30 \%$ раствора последовательным разбавлением этиловым спиртом до 7\%, в пересчете на $\mathrm{TiO}_{2}$. В качестве подложек использовали стеклянные или медные пластинки размером 2,5×2,5 cм, на которых методом центрифугирования формировали пленки из титансодержащего спиртового раствора, объем раствора 0,3 мл. Скорость вращения подложки 6000 об/мин. По данным АСМ толщина непрерывных пленок прекурсора на стекле составляет 80 - 100 нм. 
Образование кристаллических пленок $\mathrm{TiO}_{2}$ происходило в результате термолиза пленок прекурсора при температурах от $300^{\circ} \mathrm{C}$ до $500^{\circ} \mathrm{C}$ в муфельной печи СНОЛ 15/1300.

Исследование кристаллической структуры и морфологии полученных кристаллических пленок $\mathrm{TiO}_{2}$ проводили методами рентгенофазового анализа (РФА), сканирующей электронной микроскопии (СЭМ), атомно-силовой микроскопии (АСМ).

РФА образцов осуществляли на рентгеновском дифрактометре Bruker D8 ADVANCE A25 в железном фильтрованном излучении (FeКа-излучение $\lambda=0,193604$ нм, Mn фильтр). Исследования проводились в интервале углов $2 \theta 20^{\circ}-70^{\circ}$ с шагом $0,02^{\circ}$. Обработку дифрактограмм проводили с использованием пакета программ для сбора и обработки данных Diffrac.Suite.Eva (V3.1). Расшифровку дифрактограмм выполняли на основе базы данных ICDD PDF-2. Исследование морфологии поверхности пленок методами СЭМ и АСМ проводили на сканирующем электронном микроскопе JEOL JSM6390 SEM с энергодисперсионной приставкой для элементного анализа JED 2300, и на сканирующем зондовом микроскопе ФемтоСкан на воздухе, при нормальных условиях и комнатной температуре. Образцы пленок для АСМ исследования готовили на стеклянных подложках, обеспечивающих достаточную гладкость поверхности образцов. В работе применялись кантилеверы серии fpN10S жесткостью 11.5 Н/м с частотой 255 кГц.

\section{3. Результаты и обсуждения}

\section{Получение и обработка пленок прекурсора}

7\% раствор титанорганического прекурсора позволяет формировать на подложках пленки полиэтоксититана и получать из них практически непрерывные (за исключением отдельных дефектов, обнаруживаемых методом СЭМ) тонкие пленки $\mathrm{TiO}_{2}$ толщиной до 100 нм. Увеличение концентрации раствора приводит к увеличению толщины слоя прекурсора и растрескиванию пленки $\mathrm{TiO}_{2}$ в ходе термообработки из-за разных коэффициентов расширения подложки и пленки.

Стеклянные подложки обладают достаточной степенью гладкости для того, чтобы обеспечить исследование пленок методом АСМ.

Исследование тонких пленок диоксида титана методом РФА затруднено из-за малой толщины пленки (менее 100 нм), поэтому особые требования предъявляются к материалу подложки. Аморфная структура стекла накладывает аморфное широкое галло в диапазоне углов $2 \theta$ от $15^{\circ}$ до $60^{\circ}$ при регистрации рентгенограмм тонких пленок $\mathrm{TiO}_{2}$, которые без термической обработки также имеют аморфную неокристаллизованную структуру.

Для выбора оптимального материала подложки были проанализированы ренгенограммы металлических подложек, имеющихся в распоряжении авторов. Алюминиевая фольга имеет рефлексы $\mathrm{Al}\left(48,915^{\circ} ; 57,119^{\circ}\right)$ и $\mathrm{Al}_{2} \mathrm{O}_{3}$ $\left(32,265^{\circ} ; 44,265^{\circ} ; 47,956^{\circ}\right)$ в области соответствующей отражению плоскостей анатаза $\left(31,9^{\circ}\right)$, брукита $\left(32,49^{\circ}\right.$, $\left.34,99^{\circ}\right)$ и рутила $\left(34,76^{\circ}\right)$ и не позволит идентифицировать с достаточной степенью вероятности кристаллическую структуру пленки $\mathrm{TiO}_{2}$. Фольга из желтой латуни с содержанием цинка $36 \%$ оказалась удовлетворительным материалом для РФА тонких пленок $\mathrm{TiO}_{2}$, т.к. рефлексы компонентов сплава не перекрывают рефлексы ни одной из модификаций $\mathrm{TiO}_{2}$. Но следует учесть, что при формировании пленки прекурсора используется титансодержащий раствор, приготовленный из $\mathrm{TiCl}_{4}$ и этилового спирта. Более химически активный компонент материала подложки - цинк, имеет возможность реагировать с компонентами пленки прекурсора или окисляться в атмосфере воздуха, особенно при повышенных температурах. В связи с изложенным, при исследовании фазового состава тонких пленок $\mathrm{TiO}_{2}$ в качестве оптимальных подложек были использованы медные.

\section{Получение кристаллических пленок $\mathrm{TiO}_{2}$}

На рисунках 1 и 2 представлены рентгенограммы, а на рисунке 3 АСМ-изображения поверхности пленок $\mathrm{TiO}_{2}$, полученные на образцах с различными величинами температуры обработки пленок прекурсора. Следует помнить, что приготовление образцов для каждого из методов анализа проводили на оптимально подходящих для оборудования подложках, поэтому результаты полученные каждым из методов могут не полностью совпадать по значению температуры из-за влияния химической природы и структуры подложки, а также условий нагрева в присутствии или отсутствии кислорода.

Однако, как будет показано ниже, анализ полученных результатов показывает достаточное соответствие данных, полученных разными методами.

Согласно данным РФА на рентгенограммах исходных пленок $\mathrm{TiO}_{2}$ кристаллическая структура отсутствует. Это следует из аморфного галло в диапазоне углов $2 \theta$ 29,5-37,0. Исследование поверхности исходных пленок методом АСМ показывает, что они имеют практически гладкую поверхность (среднее значение шероховатости $0,16 \mathrm{нм})$.

При нагревании пленок до $300^{\circ} \mathrm{C}$ на фоне аморфной фазы появляется рефлекс на угле $2 \theta 32,0^{\circ}$, который отно-

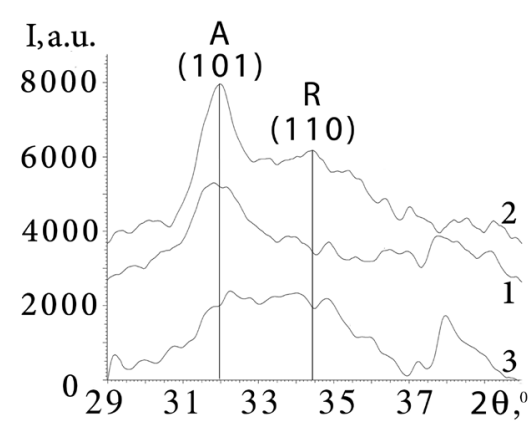

Pис. 1. Рентгенограммы пленок $\mathrm{TiO}_{2}$ на медной подложке, полученных в вакууме при различных температурах: $1-300^{\circ} \mathrm{C}$, 2 - $400^{\circ} \mathrm{C}, 3$ - пленка прекурсора без термической обработки.

Fig. 1. XRD patterns of $\mathrm{TiO}_{2}$ films obtained at different temperatures under vacuum on copper substrates: $1-300^{\circ} \mathrm{C} 2-400^{\circ} \mathrm{C}, 3-$ precursor film. 


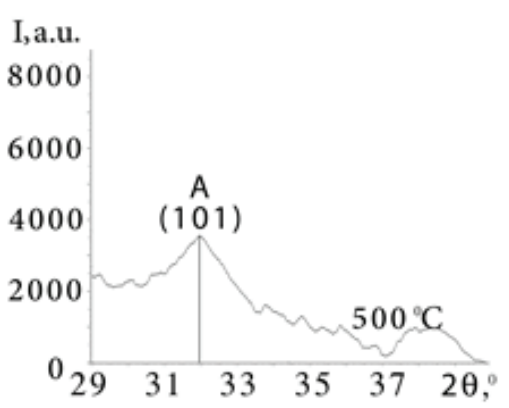

Pис. 2. Рентгенограмма пленки $\mathrm{TiO}_{2}$ на медной подложке, полученной в среде воздуха при температуре $500^{\circ} \mathrm{C}$.

Fig. 2. XRD pattern of $\mathrm{TiO}_{2}$ film obtained at temperature $500^{\circ} \mathrm{C}$ in an air atmosphere.

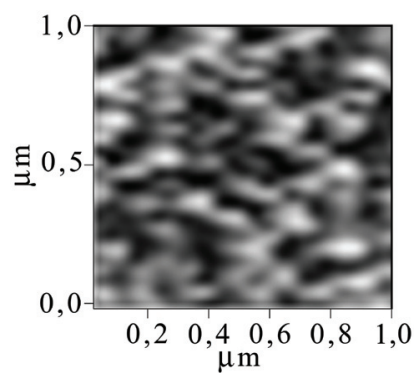

a

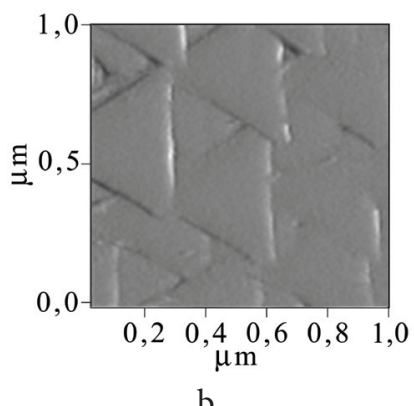

b
Рис. 3. АСМ-изображения пленок $\mathrm{TiO}_{2}$ на стеклянной подложке, полученные при различных температурах: при $400^{\circ} \mathrm{C}$ (a), при $500^{\circ} \mathrm{C}$ (б), (термообработка на воздухе).

Fig. 3. AFM images of $\mathrm{TiO}_{2}$ films obtained at different temperatures on a glass substrate: $400^{\circ} \mathrm{C}$ (a), $500^{\circ} \mathrm{C}$ (b) (heat treatment in an air atmosphere).

сится к плоскости (101) кристаллической модификации $\mathrm{TiO}_{2}$ - анатаз. Процесс образования кристаллической структуры $\mathrm{TiO}_{2}$, согласно данным АСМ, сопровождается нарастанием шероховатости пленки. Таким образом, после нагревания до $300^{\circ} \mathrm{C}$ в вакууме и на воздухе структуру пленки $\mathrm{TiO}_{2}$ можно представить как аморфную матрицу, в которой находятся отдельные кристаллиты анатаза.

Дальнейшее увеличение температуры нагрева пленки до $400^{\circ} \mathrm{C}$ в вакууме приводит к увеличению в 2 раза рефлекса (101), что можно связать со структурированием пленки анатаза (рис.1).

Следует отметить, что при температуре $400^{\circ} \mathrm{C}$ начинается не соответствие результатов РФА для пленок нагреваемых в вакууме и на воздухе. При нагревании пленки до $400^{\circ} \mathrm{C}$ в вакууме на рентгенограмме появляется новый рефлекс на $34,6^{\circ}$, соответствующий плоскости (110) фазы рутила, окончательная рутилизация происходит при температуре выше $550^{\circ} \mathrm{C}$. В тоже время пленки, нагреваемые на воздухе до $500^{\circ} \mathrm{C}$, содержат лишь фазу анатаза.

Структурирование пленки $\mathrm{TiO}_{2}$, нагреваемой в атмосфере воздуха, по данным АСМ происходит с образованием геометрически правильных однородных структур треугольной формы, ориентированных в одной плоскости (рис.3). На ренгенограмме, соответствующей этому образцу, регистрируется четко сформированный рефлекс (101), который соответствует хорошо охарактеризованной упорядоченной кристаллической структуре (рис.2). Среднее значение шероховатости поверхности пленки $\mathrm{TiO}_{2}$ в структурной модификации анатаз - 5 нм. Средний размер треугольных пластинок, образующих поверхность пленки $\mathrm{TiO}_{2}$, составляет 350 нм.

Приведенные результаты показывают, что полученные предложенным способом пленки $\mathrm{TiO}_{2}$ после нагревания до $300^{\circ} \mathrm{C}$ харакеризуются аморфно-кристаллической структурой. Увеличение температуры до $400^{\circ} \mathrm{C}$ в вакууме приводит к увеличению имеющихся кристаллитов фазы анатаза с зарождением новой фазы рутила в пленках $\mathrm{TiO}_{2}$, но не переводит ее полностью в кристаллическое состояние (рис.1.). Присутствие кислорода воздуха при термической обработке пленок стабилизирует фазу анатаза, увеличивая температуру появления рутила более чем на $100^{\circ} \mathrm{C}$. Кроме того при $500^{\circ} \mathrm{C}$ наблюдается полный переход аморфного $\mathrm{TiO}_{2}$ в кристаллический анатаз (рис.2) с образованием упорядоченной структуры поверхности (рис.3(b)).

Для пленок полученных на стеклянных подложках была протестирована химическая и механическая прочность. Следует отметить, что пленки прекурсора, сформированные на стекле, прозрачны и не обладают стойкостью к растворению в воде и спирте, а также могут быть удалены механически.

Кристаллические пленки $\mathrm{TiO}_{2}$ получаемые после термической обработки, однородно окрашены, их поверхность очень трудно повредить механически. Они имеют высокую отражательную способность. Такие пленки стабильны в растворах аммиака, кислот и других щелочей. Удаление этих пленок с подложек происходит лишь в растворе плавиковой кислоты или серной при кипячении.

Нами были получены пленки окрашенные в цвета, соответствующие всему диапазону видимого света. Однородность окраса пленок по поверхности образца подтверждает однородность их толщины. Расчетные значения энергии прямых переходов, полученные из спектров пропускания, показали, что пленки $\mathrm{TiO}_{2}$ толщиной $\approx 50$ нм имеют значение ширины запрещенной зоны $\mathrm{E}=3,9$ эВ. Полученная величина значительно превышает табличные значения для рутила $(\mathrm{E}=3,0$ эВ), анатаза $(\mathrm{E}=3,2$ эВ), брукита ( $\mathrm{E}=3,4$ эВ).

Фотоактивность, механическая прочность и низкая шероховатость поверхности получаемых пленок $\mathrm{TiO}_{2}$ позволяет наблюдать методом АСМ не только их структуру, но и локализацию продуктов реакций фотовосстановления металлических частиц или образование и разрушение агрегатов красителей, а также исследовать структурные изменения морфологии поверхности $\mathrm{TiO}_{2}$ при фазовых переходах.

\section{4. Заключение}

Показана возможность получения прозрачных кристаллических пленок $\mathrm{TiO}_{2}$ с заданной структурной модификацией в условиях контролируемого нагрева с целью последующего изучения влияния морфологии поверхности $\mathrm{TiO}_{2}$ на протекание топохимических реакций. Получены аморфные и кристаллические со структурной 
модификацией анатаз или анатаз-рутил с различным соотношением фаз пленки $\mathrm{TiO}_{2}$.

Исследована поверхность морфологически однородных кристаллических пленок анатаза с упорядоченной структурой поверхности (101), определена температура их формирования в вакууме и на воздухе.

Полученные результаты показывают возможность получения тонких кристаллических пленок диоксида титана в модификации анатаз на подложках из стекла и меди. Структура полученных пленок однородная по толщине и морфологии. Способ нанесения пленки прекурсора и условия формирования пленок $\mathrm{TiO}_{2}$ позволяют наносить их на металлические и стеклянные поверхности для придания им фотокаталитических свойств.

Благодарность. Работа выполнена на приборной базе «Центра коллективного пользования КемНЦ СО РАН» и «ЦКП научным оборудованием КемГУ».

Acknowledgements. The work has been carried out at the Centre for Collective Use of Scientific Equipment in Kemerovo Scientific Center of the Siberian Branch of the RAS and Centre for Collective Use of Scientific Equipment in Kemerovo State University.

\section{Литература / References}

1. S.S. Watson, D. Beydoun, J.A Scott, R. Amal. Chem. Eng. J. 95 (1-3), 213 - 220 (2003).
2. X. Chen, S.S. Mao. Chem. Rev. 107 (7), 2891 - 2959 (2007).

3. T. Ohno, K. Sarukawa, K. Tokieda, M. Matsumura. J. Catal. 203 (1), 82 - 86 (2001).

4. P. Kajitvichyanukula, J. Ananpattarachaia, S. Pongpom. Sci. Tech. Adv. Mater. 6, 352 - 358 (2005).

5. Qu. Xiang, J. Yu, M. Jaroniec. Chem. Commun. 47, 4532 - 4534 (2011).

6. H. Choia, E. Stathatosb, D.D. Dionysioua. Wastewater Reclamation and Reuse for Sustainability. 202 (1-3), 199 - 206 (2007).

7. H.G. Yang, C.H. Sun, S.Z. Qiao, J. Zou, G. Liu, S.C. Smith, H.M. Cheng, G.Q. Lu. Nature. 453, 638 - 641 (2008). doi:10.1038/nature06964

8. M. Kobayashi, H. Kato, M. Kakihana. Nanomater. Nanotechnol. 3, 1 - 10 (2013).

9. A. Di Paola, M. Bellardita, L. Palmisano. Catalysts. 3 (1), 36 - 73 (2013). doi:10.3390/catal3010036

10. Z. Wei, E. Kowalska, B. Ohtani. Molecules. 19, 19573 19587 (2014). doi:10.3390/molecules191219573

11. X.H. Yang, Z. Li, G. Liu, J. Xing, C.H. Sun, H.G. Yang, C.Z. Li. Cryst. Eng. Commun. 13, 1378 - 1383 (2010). doi:10.1039/C0CE00233J

12. J. Xing, H.G. Yang, G.Q. Lu (Max). Nanotechnology, SPIE Newsroom. 3894, 1 - 3 (2011). doi:10.1117/2.1201109.003894

13. A.Yu. Stepanov, L.V. Sotnikova, A.A. Vladimirov. Abstract: International Congress on Energy Fluxes and Radiation Effects. - Tomsk: Publishing House of IAO SB RAS, 2014. - P. 492. 